\title{
Sistem Informasi Geografis Menggunakan Multi Criteria Evaluation Untuk Zona Wisata Bahari Pantai Rupat
}

\author{
Roni Salambue ${ }^{1}$, Nurdin², Rangga Putra Pratama ${ }^{1}$, Benny Putra ${ }^{1}$ \\ 1 Program Studi Sistem Informasi FMIPA Universitas Riau Pekanbaru 28293 \\ 2 Program Studi Teknik Sipil Fakutas Teknik Universitas Riau Pekanbaru 28293 \\ (cooresponding author) roni.salambue@lecturer.unri.ac.id
}

\begin{abstract}
Since the separation of some districts which produced oil and gas into new districts, gave an impacts on declining of local government revenues at Bengkalis. It is the reason the government began to glance at other alternative income sources such as the tourism sectors especially marine tourism. Rupat beach has been designated as a tourism area by the Government of Bengkalis. Local Government's strategic policy in supporting Rupat beach as a marine tourism destination are by building infrastructure access roads, harbors, crossing ferry andaccomodation. This research aims to determine the marine tourism at Rupat beach using Geographic Information System (GIS). The method used is a multi-criteria evaluation to analyze the suitability of the area. The analysis results showed that areas of Teluk Rhu, Tanjung Punak, Putri Sembilan and Makeruh were suitable enough for coastal marine tourism zones but Sungai Cingam was not suitable. The areas of Teluk Rhu, Tanjung Punak and Makeruh were suitable for recreational marine tourism beaches, Sungai Cingam area was suitable enough, while, on the other hand Putri Sembilan was not.
\end{abstract}

Keyword- geographic information system, multi criteria evaluation, zone, marine tourism, rupat beach

Intisari- Sejak lepasnya beberapa kecamatan penghasil minyak dan gas menjadi kabupaten baru, memberi dampak terhadap menurunnya pendapatan Pemda Bengkalis. Sumber pemasukan alternatif lain seperti sektor pariwisata mulai dilirik khususnya wisata bahari. Pantai Rupat telah ditetapkan sebagai kawasan pariwisata oleh Pemda Kabupaten Bengkalis. Kebijakan strategis Pemda dalam mendukung Pantai Rupat sebagai destinasi wisata bahari adalah dengan membangun infrastuktur akses jalan, dermaga pelabuhan ferry penyeberangan dan penginapan. Penelitian ini bertujuan untuk menentukan zonasi kawasan wisata bahari pada Pantai Rupat menggunakan Sistem Informasi Geografis (SIG). Metode yang digunakan adalah multi criteria evaluation untuk menganalisa kesesuaian kawasan. Hasil analisis menunjukkan kawasan Teluk Rhu, Tanjung Punak, Putri Sembilan dan Makeruh dikategorikan cukup sesuai sebagai zona wisata bahari pesisir pantai namun kawasan Sungai Cingam dikategorikan sebagai zona yang tidak sesuai. Untuk zona wisata bahari rekreasi pantai kawasan Teluk Rhu, Tanjung Punak dan Makeruh dikategorikan sebagai zona yang sesuai, kawasan Sungai Cingam dikategorikan sebagai zona yang cukup sesuai dan kawasan Putri Sembilan dikategorikan sebagai zona yang tidak sesuai

Kata Kunci- sitem informasi geografis, multi criteria evaluation, zona, wisata bahari, pantai rupat,

\section{PENDAHULUAN}

Sejak lepasnya beberapa kecamatan penghasil minyak dan gas menjadi kabupaten baru, memberi dampak terhadap menurunnya pendapatan Pemda Bengkalis. Sumber pemasukan alternatif lain seperti sektor pariwisata mulai dilirik khususnya wisata bahari. Letak geografis Pulau Bengkalis yang diapit oleh selat bengkalis dan selat malaka membuat kabupaten Bengkalis mempunyai letak yang sangat strategis, karena dilalui oleh jalur perkapalan internasional menuju ke Selat Malaka. Kawasan yang menjadi andalan wisata bahari adalah Pantai Rupat.

Pulau Rupat merupakan satu pulau terluar di Indonesia yang mempunyai dua kecamatan yaitu Rupat dan Rupat Utara. Pulau ini memiliki posisi yang sangat strategis, karena berhadapan langsung dengan perairan internasional yang sangat ramai, yaitu Selat Malaka. Pulau Rupat mempunyai pantai dengan pasir putih yang membentang sepanjang $17 \mathrm{Km}$ mulai dari Desa Teluk Rhu Kecamatan Rupat Utara sampai dengan Sungai Cingam Kecamatan Rupat. Pantai dengan lebar 30 meter jika air surut atau 7 meter saat air pasang, memiliki keindahan yang tidak kalah dengan pantai-pantai di pulau Bali. Oleh karena itu Pemerintah Daerah (Pemda) Kabupaten Bengkalis menetapkan wilayah Pantai Rupat sebagai kawasan wisata bahari yang tertuang dalam dokumen Rencana Tata Ruang Wilayah (RTRW) 2011 - 2035 dan Rencana Pembangunan Jangka Menengah Daerah (RPJMD) 2010 - 2015 [1]. Dalam dokumen RPJMD terdapat lima pantai yang ditetapkan sebagai kawasan wisata bahari yang terdiri atas tiga pantai di Kecamatan Rupat Utara yaitu Teluk Rhu, Tanjung Punak dan Putri Sembilan dan dua pantai di Kecamatan Rupat yaitu Makeruh dan Sungai Cingam.

Pengembangan pulau Rupat sebagai tujuan wisata, bukan saja menjadi program pembangunan di Kabupaten Bengkalis, tetapi juga di Provinsi Riau. Hal ini dapat dilihat dari kebijakan strategis pembangunan Bengkalis maupun Riau. Karena itu berbagai fasilitas pengembangannya sudah dibangun, baik oleh Pemerintah Kabupaten Bengkalis dan 
Provinsi Riau, seperti akses jalan, dermaga pelabuhan ferry penyeberangan, restoran yang buka 24 jam dan puluhan home stay serta guest house.

Penelitian ini membahas tentang zona kesesuaian kawasan wisata bahari di pantai Rupat dengan pendekatan Sistem Informasi Geografis menggunakan metode Multi Criteria Evaluation. Parameter kesesuaian kawasan berdasarkan karakteristik pantai Rupat. Data karakteristik pantai dikumpulkan secara primer dan sekunder kemudian diolah menggunakan aplikasi ArcGIS. Informasi yang dihasilkan adalah zona wisata bahari di kawasan Pantai Rupat.

\section{TINJAUAN PUSTAKA}

Sistem Informasi Geografis (SIG) merupakan sistem yang dirancang untuk bekerja dengan data yang tereferensi secara spasial. SIG merupakan gabungan dari tiga unsur pokok: sistem, informasi, dan geografis, yang mana lebih menekankan pada unsur informasi geografis. Makna informasi geografis adalah penyajian informasi mengenai posisi suatu obyek di permukaan bumi dan atributnya [2].

Wisata bahari adalah jenis wisata minat khusus yang memiliki aktivitas yang berkaitan dengan kelautan, baik di atas permukaan laut (marine), maupun kegiatan yang dilakukan di dalam laut (submarine). Wisata bahari merupakan wisata lingkungan (eco-tourism) yang berlandaskan daya tarik bahari di lokasi atau kawasan yang didominasi kelautan [3].

Penelitian penentuan kawasan wisata bahari menggunakan SIG dilakukan di pulau wangi-wangi kabupaten Wakatobi provinsi Sulawesi Tenggara [3]. Penelitian tersebut bertujuan untuk menentukan kesesuaian kawasan untuk wisata bahari menggunakan data kecerahan perairan, tutupan terumbu karang hidup, jenis terumbu karang, jenis ikan, kecepatan arus, kedalaman dasar laut dan posisi geografis sebagai data primer. Sebagai data sekunder digunakan RPJMD, RTRW, Rencana Induk Pengembangan (RIP) Pariwisata, Dinas Kelautan, Badan Pusat Statistik (BPS) Wakatobi dan peta laut Dishidros TNI-AL Pulau Wakatobi. Metode yang digunakan dalam penelitian ini adalah metode analisis spasial (keruangan) dan analisa tabular terhadap kesesuaian kawasan dalam SIG. Hasil analisis spasial dan tabular terhadap kesesuaian kawasan untuk wisata bahari, menunjukkan bahwa terdapat lokasi yang sesuai untuk dijadikan zona wisata bahari yaitu di utara Pulau Wangi-wangi dengan luas sekitar 2.786,9 hektar atau 20,3\% dari luas total wilayah kawasan.

Penelitian lain adalah rencana pengembangan wisata bahari di kawasan perairan teluk lada Provinsi Banten dengan pendekatan SIG [4]. Penelitian ini membuat zonasi wilayah yang cocok sebagai lokasi wisata bahari menggunakan data oseanografi yaitu kecerahan air, kecepatan arus, kedalaman air, sebaran terumbu karang dan jarak pantai sebagai data primer dan data sekunder adalah citra satelit landsat, peta rupa bumi, peta lingkungan pantai Indonesia. Metode yang digunakan adalah interpolasi inverse distance weight dan distance analysis. Hasil penelitian menunjukkan bahwa di perairan teluk lada terdapat sejumlah perairan yang layak untuk dijadikan kawasan wisata bahari.

Selain itu teknologi SIG juga digunakan untuk manajemen penggunaan lahan wilayah pesisir di Provinsi Bengkulu [5]. Pada penelitian tersebut dilakukan analisis kesesuaian lahan dan spasial pada wilayah pesisir Kota Bengkulu untuk kolam ikan air payau, wisata bahari dan kawasan konservasi menggunakan SIG. Pendekatan yang digunakan dalam penelitian ini adalah analisis spasial dengan kriteria parameter kesesuaian lahan terdiri atas abiotik elemen, biotik, budaya, dan pemanfaatan ruang dokumen RTRW menggunakan teknik overlay.

Penelitian lain yang relevan adalah penggunaan metode Multi Criteria Evaluation (MCE) untuk menentukan kesesuaian wisata bahari. Metode MCE digunakan untuk mengklasifikasi kelayakan tanah untuk ternak ikan nila di Bangladesh dengan pendekatan SIG [6]. Kriteria yang digunakan adalah kulitas air, kualitas tanah, topografi, infrastruktur dan sosial ekonomi masyarakat. Data gambar yang digunakan adalah ASTER image dan dianalisis menggunakan perangkat lunak ENVI dan ArcView. Interval nilai untuk skor kesesuaian adalah 1 - 3, di mana nilai 1 menyatakan tidak sesuai, nilai 2 cukup sesuai dan nilai 3 sangat sesuai. Tingkat kesesuaian dipengaruhi oleh kriteria yang paling dominan terhadap jenis kegiatan. Kriteria yang mempunyai pengaruh yang terbesar adalah kualitas air yang menempati urutan teratas dengan memperoleh pembobotan yang terbesar, sedangkan kriteria infrastuktur dan sosial ekonomi masyarakat mempunyai pengaruh yang rendah.

Metode MCE juga digunakan untuk menganalisis kelayakan lahan dengan pendekatan SIG di Iran [7]. Pada penelitian tersebut dilakukan penggabungan metode MCE dengan metode Analytical Hierarchical Process (AHP). Metode MCE digunakan untuk menentukan kriteria yang berpengaruh yaitu kualitas tanah, kondisi iklim, dan ketersedian air. AHP digunakan untuk menentukan kriteria mana yang mempunyai pengaruh terbesar sampai dengan terendah. Pada penelitian lain telah digabungkan SIG dan Multi Criteria Decision Making (MCDM) untuk menilai kesesuaian lokasi proyek energi terbarukan pada proyek eneri surya fotovoltaik Ouarzazate di wilayah selatan Maroko [8]. Empat kriteria yang digunakan: lokasi, orography, penggunaan lahan dan iklim, serta AHP digunakan untuk menghitung bobot kriteria yang sesuai. Iklim ternyata menjadi kriteria yang paling penting karena mendefinisikan potensi produksi listrik bidang fotovoltaik. Berikutnya orography, yang mendeskripsikan kecuraman lahan dan kriteria lokasi lahan yang terletak di wilayah bagian selatan maroko. 


\section{METODE PENELITIAN}

Penelitian dilaksanakan pada bulan Mei - Agustus 2016 di Pantai Rupat dan Kabupaten Bengkalis. Peta lokasi penelitian disajikan pada Gambar 1.

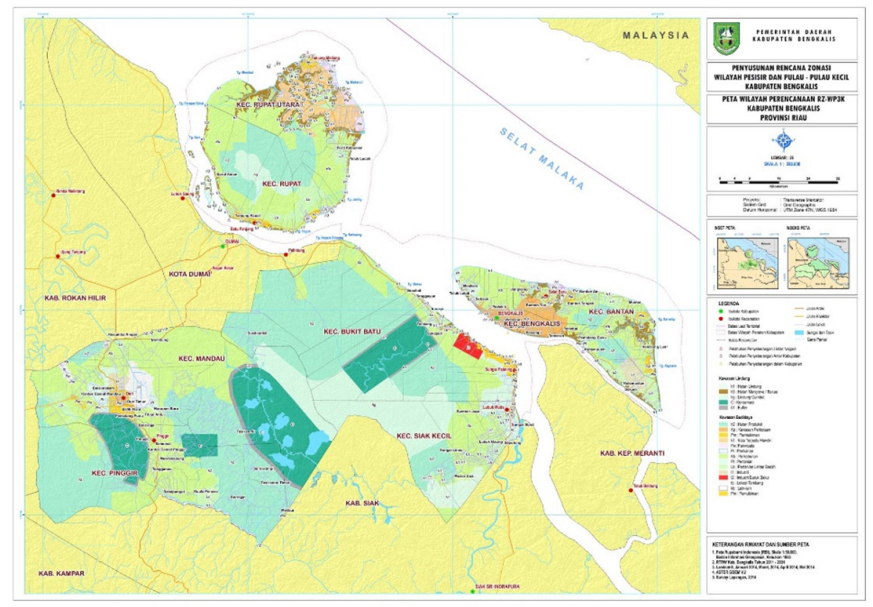

Gambar 1. Peta Lokasi Penelitian

Kegiatan pertama yang dilakukan adalah melakukan pengumpulan data data primer dan sekunder. Data primer diperoleh dengan melakukan survei lapangan ke Pantai Rupat dan data sekunder diperoleh dari instansi pemerintahan di Kabupaten Bengkalis. Jenis data primer yang dikumpulkan disajikan pada Tabel 1.

TABEL 1. DATA PRIMER

\begin{tabular}{|l|l|l|l|}
\hline No & Jenis Data & Teknik Pengumpulan & Alat yang digunakan \\
\hline $\mathbf{1}$ & Posisi Geografis & Ploting & GPS \\
\hline $\mathbf{2}$ & Lebar Pantai & Pengukuran & Spedometer \\
\hline $\mathbf{3}$ & Jarak Pantai dari Tepian & Pengukuran & Meteran \\
\hline $\mathbf{4}$ & Ketersediaan Air Tawar & Survey & Kuisioner \\
\hline $\mathbf{5}$ & Ketersediaan Sarana Pendukung & Survey & Kuisioner \\
\hline $\mathbf{6}$ & Biota Berbahaya & Survey & Kuisioner \\
\hline
\end{tabular}

Berdasarkan Tabel 1 ada tiga parameter yang diambil yang mempunyai fungsi sebagai faktor pendukung keberhasilan wisata bahari yaitu ketiadaan biota berbahaya, ketersediaan air tawar dan ketersediaan sarana pendukung. Hasil pengumpulan data primer disajikan pada Tabel berikut.

TABEL 2. HASIL PENGUMPULAN DATA PRIMER

\begin{tabular}{|r|l|l|}
\hline No & Parameter & Hasil Survey \\
\hline $\mathbf{1}$ & Lebar Pantai & $\pm 13 \mathrm{Km}$ \\
\hline $\mathbf{2}$ & Jarak Pantai dari Tepian & $3-5 \mathrm{~m}$ \\
\hline $\mathbf{3}$ & Ketersediaan Air Tawar & Ada \\
\hline $\mathbf{4}$ & Ketersediaan Sarana Pendukung & $\begin{array}{l}\text { Ada: Penginapan, Rumah } \\
\text { Makan dan Mesjid }\end{array}$ \\
\hline $\mathbf{5}$ & Biota Berbahaya & Tidak ada \\
\hline $\mathbf{6}$ & Ketersediaan Terumbu Karang & Tidak ada \\
\hline $\mathbf{7}$ & Jenis Pasir Pantai & Putih \\
\hline $\mathbf{8}$ & Sebaran Penduduk & $\pm 500 \mathrm{KK}$ \\
\hline
\end{tabular}

Data sekunder diperoleh dari instansi pemerintahan Kabupaten Bengkalis yaitu Badan Perencanaan Pembangunan Daerah (BAPPEDA), Dinas Kebudayaan, Pariwisata, Pemuda dan Olahraga, Dinas Kelautan dan Perikanan, Badan Pusat Statistik (BPS). Selain dari instansi pemerintahan Kabupaten Bengkalis, khusus untuk peta Rupabumi diperoleh dari Badan Informasi Geospasial (BIG). Jenis data sekunder yang dikumpulkan disajikan pada Tabel 3. 
TABEL 3. DATA SEKUNDER

\begin{tabular}{|l|l|l|}
\hline No & Jenis Data & Sumber Data \\
\hline $\mathbf{1}$ & Peta Rupabumi Indonesia (1983) skala 1:50.000 & BIG \\
\hline $\mathbf{2}$ & RPJMD Kabupaten Bengkalis Tahun 2010 - 2015 & BAPPEDA \\
\hline $\mathbf{3}$ & Draft Rencana Tata Ruang Wilayah (RTRW) 2014- 2034 & BAPPEDA \\
\hline $\mathbf{4}$ & $\begin{array}{l}\text { Penyusunan Rencana Induk Pengembangan Pariwisata Kabupaten } \\
\text { Bengkalis }\end{array}$ & $\begin{array}{l}\text { Dinas Kebudayaan Pariwisata Pemuda } \\
\text { dan Olahraga }\end{array}$ \\
\hline $\mathbf{5}$ & $\begin{array}{l}\text { Dokumen Awal Rencana Zonasi Wilayah Pesisir dan Pulau-Pulau } \\
\text { Kecil Kabupaten Bengkalis Tahun 2014 }\end{array}$ & Dinas Kelautan dan Perikanan \\
\hline $\mathbf{6}$ & Kecamatan Rupat dan Rupat Utara dalam Angka 2015 & BPS \\
\hline
\end{tabular}

Pada peta Rupabumi terdapat beberapa parameter oseanografi yang digunakan sebagai parameter kesesuaian jenis wisata bahari di Pantai Rupat Utara yaitu kecerahan perairan, kedalaman laut dan kecepatan arus. Pemilihan ketiga parameter itu berdasarkan Keputusan Menteri Negara Lingkungan Hidup Nomor 51 Tahun 2004 Tentang Baku Mutu Air Laut untuk wisata bahari [9]. Ketiga parameter tersebut cukup representatif untuk menentukan dua jenis wisata bahari yaitu wisata pesisir pantai (snorkling, dan selam) atau wisata rekreasi pantai (berjemur dan renang). Namun pada penelitian ini digunakan empat parameter untuk menentukan kesesuaian wisata bahari yang terdiri dari tiga parameter diatas dan ditambah parameter ketersediaan terumbu karang untuk jenis wisata pesisir pantai dan parameter jarak pantai dari tepian untuk jenis wisata rekreasi pantai. Parameter ketersedian terumbu karang diperoleh dari data sekunder dan di verifikasi ke masyarakat pada saat pengumpulan data primer. Sedangkan parameter jarak pantai dari tepian diperoleh dari pengumpulan data primer.

Kesesuaian jenis kegiatan wisata bahari dianalisis dengan metode MCE [5]. Metode ini menggunakan pembobotan pada parameter yang berpengaruh dan skor kesesuaian pada setiap kriteria yang ditentukan. Interval nilai untuk skor kesesuaian adalah 1 - 4, di mana nilai 1 menyatakan tidak sesuai (S4), nilai 2 cukup sesuai (S3), nilai 3 sesuai (S2) dan nilai 4 sangat sesuai (S1) [6] [10]. Tingkat kesesuaian dipengaruhi oleh faktor-faktor yang paling dominan terhadap jenis kegiatan wisata bahari tersebut. Faktor-faktor dengan tingkat pengaruh yang terbesar akan menempati urutan teratas dengan memperoleh pembobotan yang terbesar. Sedangkan faktor-faktor dengan tingkat pengaruh yang rendah atau kecil akan menempati urutan berikutnya. Hasil kesesuaian kegiatan wisata bahari diperoleh dengan mengombinasikan nilai bobot dan skor. Formula yang digunakan adalah:

$$
K=\sum\left(W_{i} Y_{i}\right)
$$

dimana :

$\mathrm{K}=$ kesesuaian kegiatan wisata

$\mathrm{W}_{\mathrm{i}}=$ nilai bobot untuk setiap faktor berpengaruh

$\mathrm{Y}_{\mathrm{i}}=$ nilai skor untuk setiap kriteria kesesuaian yang ditentukan

Matriks kelayakan dan pembobotan jenis kegiatan wisata bahari mengacu pada [10] dengan sedikit mengalami modifikasi. Tabel 4 dan 5 berikut memperlihatkan matriks kesesuaian jenis kegiatan wisata bahari tersebut.

TABEL 4. MATRIKS KESESUAIAN WISATA PESISIR PANTAI

\begin{tabular}{|c|c|c|c|c|c|c|c|c|c|c|}
\hline \multirow{2}{*}{ No } & \multirow{2}{*}{ Parameter } & \multirow{2}{*}{$\begin{array}{c}\text { Bobot } \\
(\%)\end{array}$} & \multicolumn{2}{|l|}{ S1 } & \multicolumn{2}{|l|}{ S2 } & \multicolumn{2}{|l|}{ S3 } & \multicolumn{2}{|l|}{ S4 } \\
\hline & & & Kriteria & Skor & Kriteria & Skor & Kriteria & Skor & Kriteria & Skor \\
\hline 1. & Kecerahan (m) & 50 & $>6$ & 4 & $1-6$ & 3 & 1 & 2 & $<1$ & 1 \\
\hline 2. & Kedalaman dasar laut (m) & 25 & $10-25$ & 4 & $5-10$ & 3 & $2-5$ & 2 & $25<x<2$ & 1 \\
\hline 3. & $\begin{array}{l}\text { Ketersediaan Terumbu } \\
\text { Karang }\left(\mathrm{km}^{2}\right)\end{array}$ & 15 & $>0,0106$ & 4 & $\begin{array}{r}0,0052- \\
0,0106\end{array}$ & 3 & $\begin{array}{r}0,0017- \\
0,0052\end{array}$ & 2 & $<0,0017$ & 1 \\
\hline 4. & Kecepatan arus (cm/det) & 10 & $0-20$ & 4 & $20-30$ & 3 & $30-50$ & 2 & $>50$ & 1 \\
\hline & Total & 100 & & & & & & & & \\
\hline
\end{tabular}

TABEL 5. MATRIKS KESESUAIAN WISATA REKREASI PANTAI

\begin{tabular}{|c|c|c|c|c|c|c|c|c|c|c|}
\hline \multirow{2}{*}{ No } & \multirow{2}{*}{ Parameter } & \multirow{2}{*}{$\begin{array}{c}\text { Bobot } \\
\text { (\%) }\end{array}$} & \multicolumn{2}{|c|}{ S1 } & \multicolumn{2}{|l|}{ S2 } & \multicolumn{2}{|l|}{ S3 } & \multicolumn{2}{|c|}{ S4 } \\
\hline & & & Kriteria & Skor & Kriteria & Skor & Kriteria & Skor & Kriteria & Skor \\
\hline 1. & Jarak pantai (m) & 50 & $0-3$ & 4 & $3-5$ & 3 & $5-6$ & 2 & $>6$ & 1 \\
\hline 2. & Kedalaman dasar laut (m) & 25 & $1-2$ & 4 & $2-3$ & 3 & $3-4$ & 2 & $>4$ & 1 \\
\hline 3. & Kecerahan (m) & 15 & $>6$ & 4 & $1-6$ & 3 & 1 & 2 & $<1$ & 1 \\
\hline 4 & Kecepatan arus (cm/det) & 10 & $0-20$ & 4 & $20-30$ & 3 & $30-50$ & 2 & $>50$ & 1 \\
\hline & Total & 100 & & & & & & & & \\
\hline
\end{tabular}




\section{HASIL DAN ANALISA}

Setelah data primer dan sekunder terkumpul, tahapan berikutnya adalah pengolahan terhadap data tersebut. Penentuan jenis wisata bahari difokuskan pada kawasan wisata bahari yang telah ditetapkan oleh Pemda Bengkalis dalam Draft RTRW dan RPJMD. Nilai parameter oseanografi yang diambil adalah nilai yang ada pada kawasan wisata tersebut. Langkah pertama yang dilakukan menyusun peta tematik wilayah Pulau Rupat menggunakan software ArcGIS 10.2.2. Peta tematik mempunyai skala 1:150.000 yang hasilnya dapat dilihat pada Gambar berikut.

PETA RENCANA TATA RUANG \& WILAYAH PULAU RUPAT

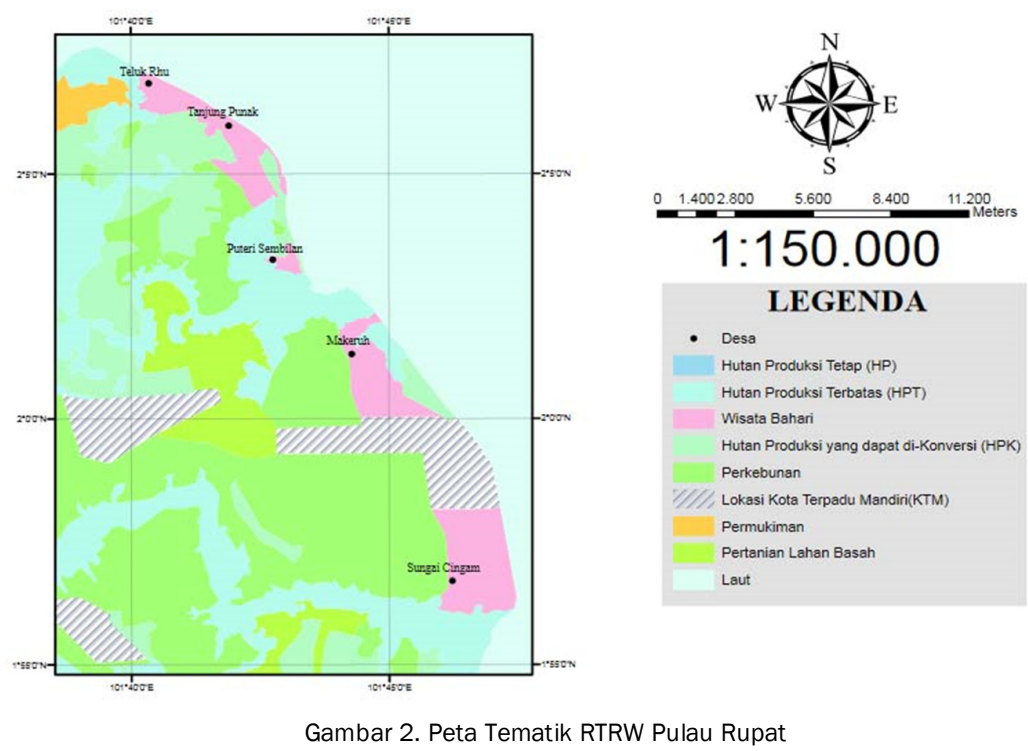

Gambar 2 memperlihatkan wilayah kawasan wisata bahari yang diarsir menggunakan legenda warna pink. Terdapat lima kawasan wisata bahari yang terdiri atas empat kawasan di Kecamatan Rupat Utara yaitu Teluk Rhu, Tanjung Punak, Putri Sembilan dan Makeruh dan satu di Kecamatan Rupat yaitu Sungai Cingam. Tahapan selanjutnya adalah membuat peta tematik berdasarkan parameter oseanografi yang diperoleh dari peta Rupabumi. Ada tiga parameter yang diekstrak melalui peta Rupabumi yaitu kecerahan perairan, kedalaman laut dan kecepatan arus. Berdasarkan tiga parameter tersebut disusunlah peta tematik setiap parameter yang disajikan pada Gambar berikut ini.

PETA KECERAHAN AIR LAUT PULAU RUPAT

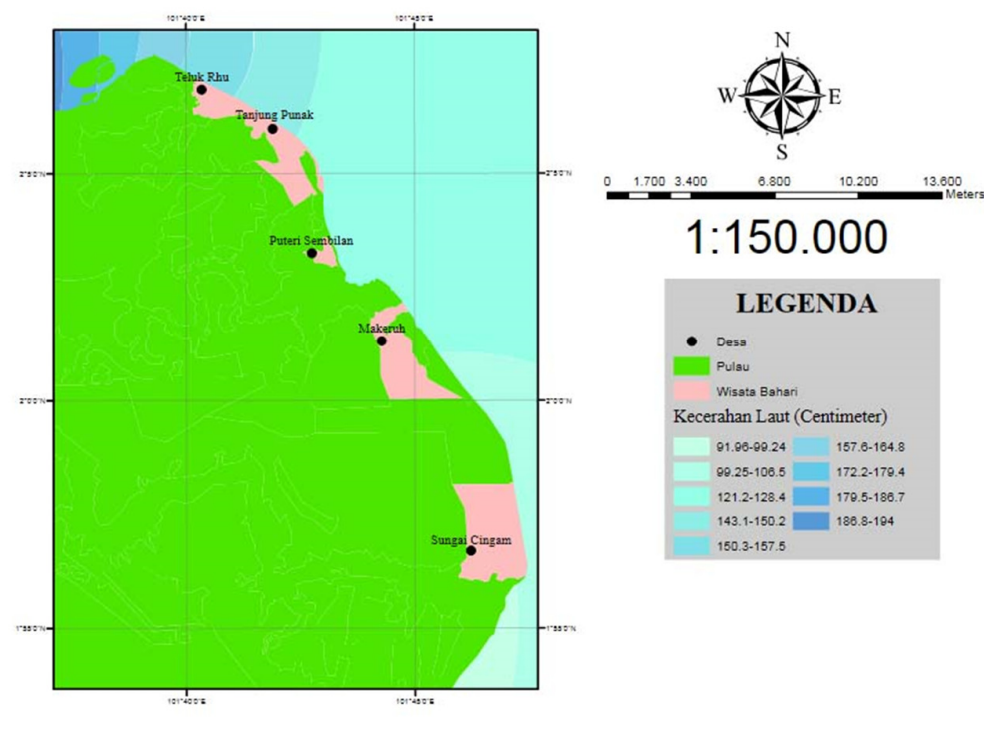

Gambar 3. Peta Tematik Kecerahan Perairan 
Berdasarkan Gambar 3 terlihat bahwa kecerahan yang paling baik dari lima kawasan wisata bahari di Pantai Rupat terdapat pada Pantai Teluk Rhu dengan interval nilai kecerahan 150,3 - 157,5 cm (1,5 - 1,57 m).

\section{PETA KEDALAMAN LAUT PULAU RUPAT}

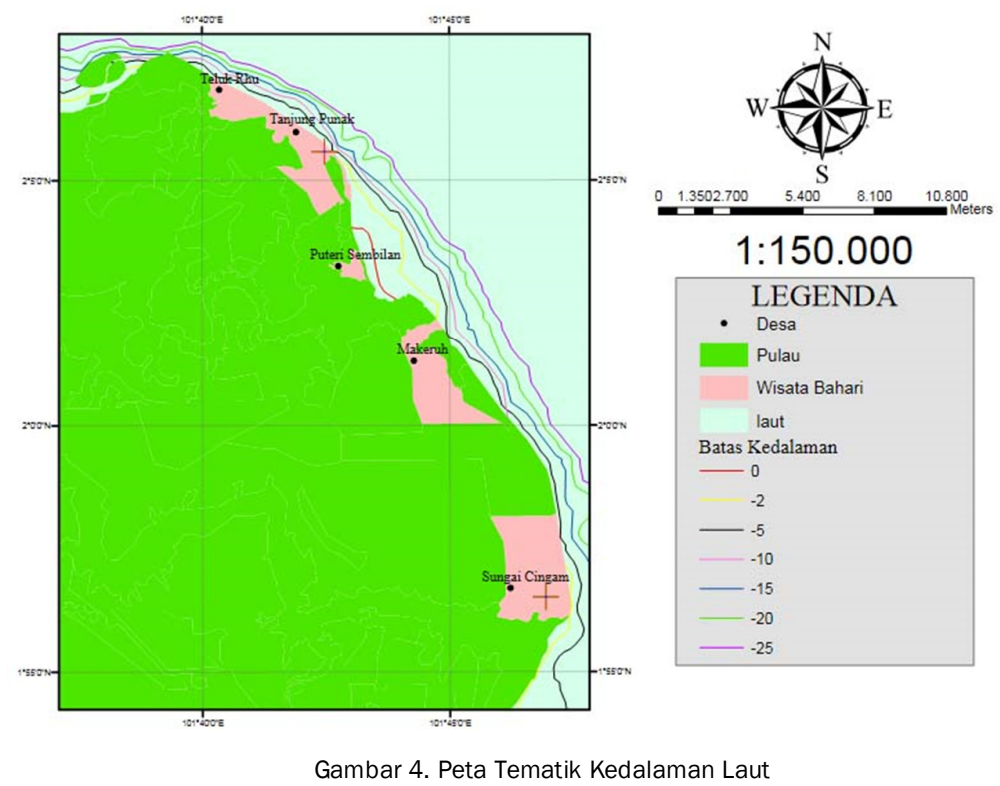

Gambar 4 memperlihatkan kedalaman laut di lima kawasan tersebut berada di interval 0-5 meter. Nilai kedalaman laut yang paling dangkal terdapat pada pantai Putri Sembilan dengan nilai kedalaman berada di interval 0-2 m. Sementara untuk kecepatan arus, nilainya relatif sama pada semua perairan Pantai Rupat yaitu 0,202 m/detik. Peta tematik kecepatan arus dapat dilihat pada Gambar 5 .

PETA KECEPATAN ARUS PULAU RUPAT

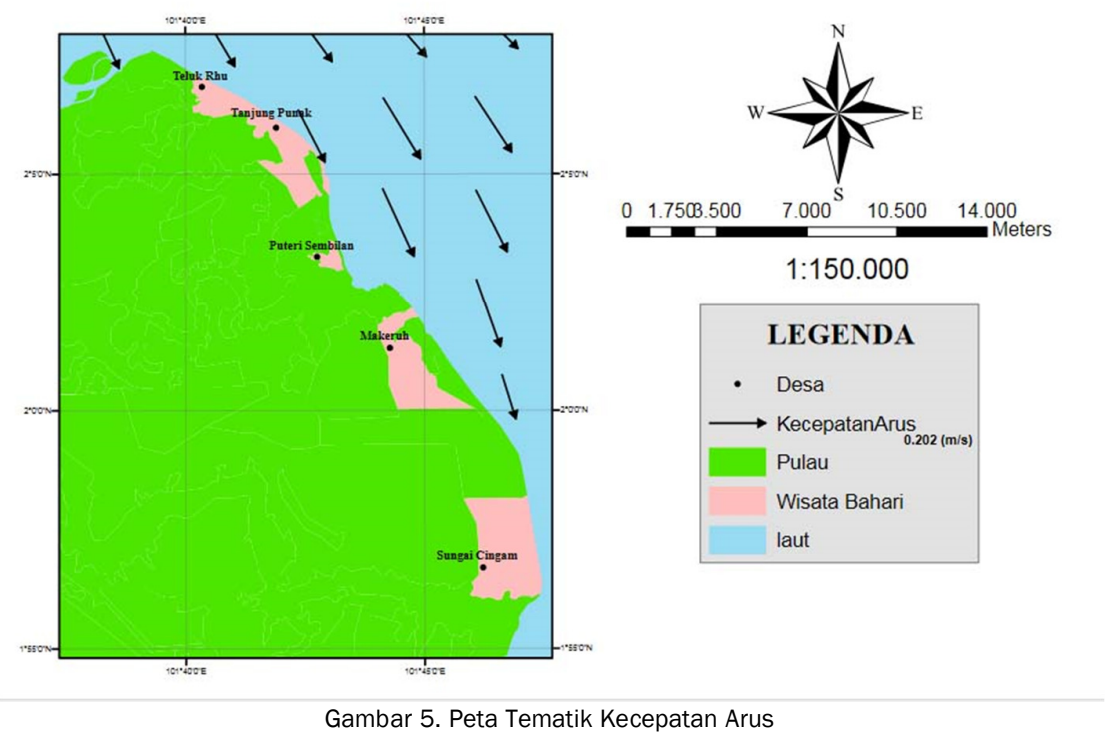

Penentuan kesesuaian lahan wisata bahari menggunakan metode MCE. Kesesuaian kawasan yang dihasilkan merupakan kesesuaian aktual berdasarkan hasil dari pembobotan masing-masing kriteria. Hasil penilaian kesesuaian kawasan wisata bahari disajikan pada Tabel 6 dan 7. 
TABEL 6. PENILAIAN KESESUAIAN WISATA BAHARI PESISIR PANTAI

\begin{tabular}{|c|c|c|c|c|c|c|c|c|c|c|c|c|c|c|c|c|c|}
\hline \multirow[b]{2}{*}{ No } & \multirow{2}{*}{ Parameter } & \multirow{2}{*}{$\begin{array}{l}\text { Bobot } \\
\text { (\%) }\end{array}$} & \multicolumn{3}{|c|}{$\begin{array}{l}\text { Teluk Rhu } \\
\end{array}$} & \multicolumn{3}{|c|}{ Tanjung Punak } & \multicolumn{3}{|c|}{$\begin{array}{c}\text { Putri Sembilan } \\
\end{array}$} & \multicolumn{3}{|c|}{ Makeruh } & \multicolumn{3}{|c|}{$\begin{array}{l}\text { Sungai Cingam } \\
\end{array}$} \\
\hline & & & Kriteria & Skor & Nilai & Kriteria & Skor & Nilai & Kriteria & Skor & Nilai & Kriteria & Skor & Nilai & Kriteria & Skor & Nilai \\
\hline 1. & Kecerahan $(\mathrm{m})$ & 50 & $1,5-1,57$ & 3 & 150 & $1,43-1,5$ & 3 & 150 & $1,21-1,28$ & 3 & 150 & $1,21-1,28$ & 3 & 150 & $0,99-1,06$ & 1 & 50 \\
\hline 2. & Kedalaman dasar laut (m) & 25 & $2-5$ & 2 & 50 & $2-5$ & 2 & 50 & $0-2$ & 1 & 25 & 5 & 3 & 75 & $2-5$ & 2 & 50 \\
\hline 3. & $\begin{array}{l}\text { Ketersediaan Terumbu } \\
\text { Karang }\left(\mathrm{km}^{2}\right)\end{array}$ & 15 & 0 & 1 & 15 & 0 & 1 & 15 & 0 & 1 & 15 & 0 & 1 & 15 & 0 & 1 & 15 \\
\hline 4. & Kecepatan arus (cm/det) & 10 & 20,2 & 3 & 30 & 20,2 & 3 & 30 & 20,2 & 3 & 30 & 20,2 & 3 & 30 & 20,2 & 3 & 30 \\
\hline & Total & 100 & & & 245 & & & 245 & & & 220 & & & 270 & & & 145 \\
\hline
\end{tabular}

TABEL 7. PENILAIAN KESESUAIAN WISATA BAHARI REKREASI PANTAI

\begin{tabular}{|c|c|c|c|c|c|c|c|c|c|c|c|c|c|c|c|c|c|}
\hline \multirow{2}{*}{ No } & \multirow{2}{*}{ Parameter } & \multirow{2}{*}{$\begin{array}{l}\text { Bobot } \\
\text { (\%) }\end{array}$} & \multicolumn{3}{|c|}{ Teluk Rhu } & \multicolumn{3}{|c|}{ Tanjung Punak } & \multicolumn{3}{|c|}{ Putri Sembilan } & \multicolumn{3}{|c|}{ Makeruh } & \multicolumn{3}{|c|}{ Sungai Cingam } \\
\hline & & & Kriteria & Skor & Nilai & Kriteria & Skor & Nilai & Kriteria & Skor & Nilai & Kriteria & Skor & Nilai & Kriteria & Skor & Nilai \\
\hline 1. & Jarak pantai $(\mathrm{m})$ & 50 & $0-3$ & 4 & 200 & $0-3$ & 4 & 200 & $>6$ & 1 & 50 & $0-3$ & 4 & 200 & $3-5$ & 3 & 150 \\
\hline 2. & Kedalaman dasar laut (m) & 25 & $2-5$ & 2 & 50 & $2-5$ & 2 & 50 & $0-2$ & 1 & 25 & 5 & 3 & 75 & $2-5$ & 2 & 50 \\
\hline 3. & Kecerahan $(\mathrm{m})$ & 15 & $1,5-1,57$ & 3 & 45 & $1,43-1,5$ & 3 & 45 & $1,21-1,28$ & 3 & 45 & $1,21-1,28$ & 3 & 45 & $0,99-1,06$ & 1 & 15 \\
\hline 4. & Kecepatan arus $(\mathrm{cm} / \mathrm{det})$ & 10 & 20,2 & 3 & 30 & 20,2 & 3 & 30 & 20,2 & 3 & 30 & 20,2 & 3 & 30 & 20,2 & 3 & 30 \\
\hline & Total & 100 & & & 325 & & & 325 & & & 150 & & & 325 & & & 245 \\
\hline
\end{tabular}

Berdasarkan Tabel 6 terlihat nilai kesesuaian wisata bahari pesisir pantai pada kawasan Teluk Rhu, Tanjung Punak, Putri Sembilan dan Makeruh mempunyai nilai dalam interval 200 - 299 sehingga empat kawasan ini dikategorikan sebagai kawasan yang cukup sesuai (S3) untuk jenis wisata bahari pesisir pantai. Namun untuk kawasan Sungai Cingam yang mempunyai nilai 145 dikategorikan sebagai kawasan yang tidak sesuai (S4) untuk jenis wisata bahari pesisir pantai.

Pada Tabel 7 meperlihatkan nilai kesesuaian wisata bahari rekreasi pantai pada kawasan Teluk Rhu, Tanjung Punak dan Makeruh mempunyai nilai dalam interval 300 - 399 sehingga ketiga kawasan tersebut dikategorikan sebagai kawasan yang sesuai (S2) untuk jenis wisata bahari rekreasi pantai. Kawasan Sungai Cingam yang mempunyai nilai 245 dikategorikan sebagai kawasan yang cukup sesuai (S3) untuk jenis wisata bahari rekreasi pantai, namun kawasan Putri Sembilan dikategorikan sebagai kawasan yang tidak sesuai (S4) untuk jenis wisata bahari rekreasi pantai.

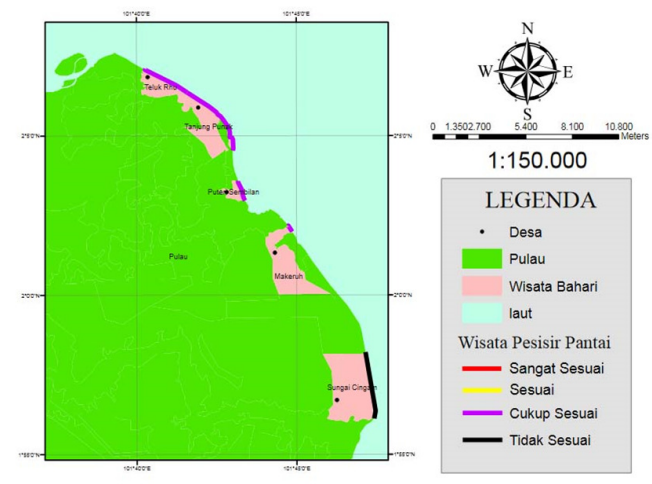

Gambar 6. Zona Wisata Bahari Pesisir Pantai

Kawasan yang dinyatakan cukup sesuai untuk jenis wisata bahari pesisir pantai ditandai dengan garis berwarna ungu dan yang tidak sesuai ditandai dengan garis berwarna hitam. 


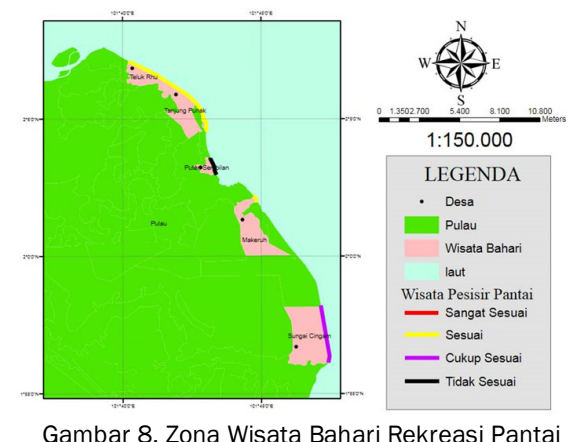

Kawasan yang dinyatakan sesuai untuk wisata bahari rekreasi pantai ditandai dengan garis warna kuning, cukup sesuai dengan garis berwarna ungu dan tidak sesuai ditandai dengan garis berwarna hitam. Secara umum pantai yang menjadi kawasan wisata bahari mempunyai panjang pesisir yang bervariasi. Panjang pesisir diperoleh dengan mengukur posisi koordinat latitude dan longitude pada titik pertama dan titik kedua pada tiap kawasan menggunakan perangkat lunak ArcGIS. Panjang pesisir pantai kawasan disajikan pada Tabel berikut.

TABEL 10 PANJANG PESISIR PANTAI KAWASAN WISATA BAHARI
\begin{tabular}{|r|l|l|}
\hline No & Kawasan & Panjang $(\mathbf{K m})$ \\
\hline 1 & Teluk Rhu & 2,8 \\
\hline 2 & Tanjung Punak & 4,6 \\
\hline 3 & Putri Sembilan & 1,3 \\
\hline 4 & Makeruh & 0,5 \\
\hline 5 & Sungai Cingam & 3,9 \\
\hline
\end{tabular}

\section{KESIMPULAN}

Berdasarkan hasil penelitian dapat diambil kesimpulan bahwa tiga kawasan di Kecamatan Rupat Utara yaitu Teluk Rhu, Tanjung Punak dan Putri Sembilan dikategorikan cukup sesuai sebagai zona wisata bahari pesisir pantai. Kawasan di Kecamatan Rupat Makeruh juga dikategorikan cukup sesuai sebagai zona wisata bahari pesisir pantai, namun untuk kawasan Sungai Cingam dikategorikan sebagai zona yang tidak sesuai untuk jenis wisata bahari pesisir pantai. Untuk zona wisata bahari rekreasi pantai kawasan Teluk Rhu, Tanjung Punak dan Makeruh dikategorikan sebagai zona yang sesuai, kawasan Sungai Cingam dikategorikan sebagai zona yang cukup sesuai dan kawasan Putri Sembilan dikategorikan sebagai zona yang tidak sesuai.

\section{UCAPAN TERIMA KASIH}

Penulis mengucapkan terimakasih kepada DRPM Kemenristek Dikti yang telah membiayai penelitian ini

REFERENSI

[1] Pemerintah Daerah Kabupaten Bengkalis, Rencana Pembangunan Jangka Menengah Daerah Kabupaten Bengkalis 2010 - 2015.2011.

[2] A. R. Tanaamah, R. Wardoyo, F. T. Informasi, U. Kristen, S. Wacana, and J. Diponegoro, "Perancangan Dan Implementasi Webgis Pariwisata Kabupaten Sumba Timur," J. Inform., vol. 9, pp. 150-158, 2008.

[3] Y. Yulius, H. L. Salim, M. Ramdhani, T. Arifin, and D. Purbani, “Aplikasi Sistem Informasi Geografis Dalam Penentuan Kawasan Wisata Bahari Di Pulau Wangiwangi, Kabupaten Wakatobi," Maj. IIm. Globe, vol. 15, no. 2, pp. 129-136, 2013.

[4] M. J. Elly, "Rencana Pengembangan Wisata Bahari di Kawasan Perairan Teluk Lada, Banten Dengan Pendekatan Sistem Informasi Geografis," IPB, 2006.

[5] Y. Fauzi, B. Susilo, and M. Mayasari, “Analisis Kesesuaian Lahan Wilayah Pesisir Kota Bengkulu Melalui Perancangan Model Spasial dan Sistem Informasi Geografis (SIG)," Forum Geogr., vol. 23, no. 2, pp. 101-111, 2009.

[6] M. S. Hossain, S. R. Chowdhury, N. G. Das, and M. M. Rahaman, "Multi-criteria evaluation approach to GIS-based land-suitability classification for tilapia farming in Bangladesh," Aquac. Int., vol. 15, no. 6, pp. 425-443, 2007.

[7] B. Feizizadeh and T. Blaschke, "Land suitability analysis for Tabriz County, Iran: a multi-criteria evaluation approach using GIS.," J. Environ. Plan. Manag., vol. 56, no. 1, pp. 1-23, 2013.

[8] M. Tahri, M. Hakdaoui, and M. Maanan, "The evaluation of solar farm locations applying Geographic Information System and Multi-Criteria Decision-Making methods: Case study in southern Morocco," Renew. Sustain. Energy Rev., vol. 51, pp. 1354-1362, 2015.

[9] K. N. L. Hidup, Keputusan Menteri Negara Lingkungan Hidup Nomor 51 Tahun 2004 Tentang Baku Mutu Air Laut. Jakarta, vol. 0. 2004.

[10] B. Ratnasari, Arlina; Nirmala, Kukuh; Budiman, Syarif; Emiyati; Hasyim, "Pemanfaatan Data Penginderaan Jauh dan Sistem Informasi Geografis Untuk Penentuan Lokasi Budidaya Rumput Laut di Perairan Teluk Gerupuk, Pulau Lombok, Provinsi Nusa Tenggara Barat," Semin. Nas. Penginderaan Jauh, pp. 710-720, 2014. 